vessels were so numerous that under a high magnifying power the unstained tissue appeared to be constituted simply of their walls. In a number of places, here and there, the wall limiting the larger vessels was somewhat reddened, and oval nuclei projected in a way, the margin of the cavity being all the time on the surface of the wall. The cavity of the vessels was perfectly empty; there were no traces of blood.

We sought in vain for a wall limiting the large central cavity. The tissue appeared to be notched at the periphery of this cavity, and differed in no respect from that of the rest of the shell. At the extremity where the tumour was implanted, and which formed one of the poles of the oval, the tissue became denser, and was constituted simply of a fibrous tissue, of which the layers had a longitudinal direction parallel to the long axis of the fragment, and analogous in staining to the islets disseminated through the rest of the shell.

The growth was, en részmé, an angiomatous polypus, with fibrous portions.

The bistological examination was therefore very conclusive, and enabled us to lay aside the idea of a wound of the jugular, as one might have thought at first, on account of the abundance of the hæmorrhage produced by the surgical intervention. We know, at the same time, that though there may not be cases of aneurism of this vessel of such a size as to project from the orifice of the external meatus, there are some sufficiently large to fill the tympanum, and to give rise to accidents at the moment when the membrane is perforated. Everybody knows, in fact, the cases of Ludwig, ${ }^{1}$ and of Hildebrandt, ${ }^{2}$ without referring to the more recent ones narrated and discussed at the meeting of the Austrian Society of Otology a few months ago. Be this as it may, the case I now narrate is sufficiently different from those that we observe in ordinary practice to deserve being communicated to you, if it were only to lead to the publication of analogous cases, if any of you have met with such in the exercise of our speciality.

Dundas Grant (Trans.).

\title{
THE SENSITIYENESS OF DEAF MUTES AND THEIR LEGAL STATUS.
}

\author{
Prof. S. Ottolenghi (Siena).
}

Read before the Fifth International Congress of Otology, Florence, 1895.

I HAVE examined the reactions for general and painful sensations in fortyfour deaf mutes with the Faradimeter of Edelmann, and I have examined the retinal sensitiveness (field of vision) with the instrument of Landolt, to see if in either case there were any marks of degeneration. My conclusions are as follows:-The reactions to general sensitiveness and to pain, in the deaf mute, are very little inferior to the normal. In early life, indeed, there is no difference worthy of note. So also with regard in general to the field of vision; it is normal both in extent and form, except for a readiness to fatigue, which by itself is anything but a serious

1 "Archiv für Ohrenheilk," Vol. XXIX., Part 3, 1890.

2 "Archiv für Ohrenheilk," Vol. XXX., Part 3, 1890. 
sign of marked degeneration. The sensitiveness of the deaf mute evidently expresses a mental development of a very satisfactory quality, and clearly differentiates him from such classes as the criminals, the epileptics, and the feeble minded (partial imbeciles), not to mention more marked forms of degeneration. In spite of the absence of one sense, the sensitive zone of the deaf mute is not deficient. Various stimuli from all the sources in the sensorium reach his cortex, and this is in such condition as to be able to normally elaborate the stimuli; hence comes ease of perception and attention. All the other sensorial sources, if exercised, can supply the want of a source so full of ideas as is that of hearing. when the centre is normal. This fact should help our judgment in forming the scientific diagnosis of the deaf mute. It has been known to the teachers of the deaf and dumb for some time, and repeatedly taught by them ; but biologists, and still less legislators, so far, have failed to bear it in mind. Deaf-mutism, by itself, does not mean serious degeneration. It is true that it may be a complication of grave forms of degeneration (imbecility, cretinism); but then the degeneration is not settled from the deaf-mutism by itself, but from the arrest or deviation of development produced by the mental deficiency to which it is united.

Just as we do not call a person a cretin because he has atrophy of the thyroid gland so we do not consider a deaf mute an imbecile because some imbeciles are affected with deaf-mutism. Probably, the great mistakes which have been made with regard to deaf mutes originated from having confused idiots with deaf-mutism, i.e., with true, genuine deaf mutes. In idiocy (imbeciles, cretins) education can do very little ; they are born poor in spirit, and so they are destined to remain. The deaf mutes, on the contrary, are individuals who are deficient in that sense which is the best for putting them en rapport with society. Hence they appear unsocial, while they are not that at all. They have all the dispositions of civilized man. If left uneducated they will be deficient, because they cannot utilize the advantages of social existence. If educated-i.e., if their faculties are exercised-the latter develop, and not only does the effect of the forced arrest of development to a great extent disappear, but their mental condition reaches a degree little inferior to normal. Education and instruction cannot manufacture intelligence, but they allow the psychical faculties to show themselves, and by being exercised to grow in strength.

In view of these facts, what shall we say when we think that, of the fifteen thousand deaf mutes in Italy, only about fifteen hundred benefit by instruction? What shall we say of the civil and penal codes which treat deaf mutes as inferiors, worse than idiots? I say worse, because for the latter at least is reserved the decision of the judge as to their civil and penal capacity when any special circumstance occurs. Deaf mutes, on the contrary, are, as a general rule, at once set down for all their lives as so much inferior that from a civil point of view they are thought to be always in need of guardianship, and as to their penal responsibility they are treated as children, even when they have reached adult life.

From my studies I feel justified in drawing the following conclusions : 
1. The deaf mute, as a rule, is endowed with organic and mental sensitiveness little inferior to the normal ; often it is quite normal.

2. It is both just and necessary to reinstate him in civil life and in his penal responsibility.

3. As it has been demonstrated that the sensitiveness of the deaf mute varies very little from the normal, and as it is known how great an influence the senses have on mental development in all systems of education, we ought to give much attention to "gymnastics" of the senses, not only for the purpose of instruction by the oral method, but because they are one of the most efficacious methods for promoting psychical development.

4. Bearing in mind the individual varieties in sensitiveness in deaf mutes, it is useful to divide them into different categories for purposes of instruction, in this way assisting the teacher, and rendering the instruction more advantageous to the pupil.

5 . In view of the conditions of the principal organs of sensation in deaf mutes, we have a greater obligation to see that they enjoy an education which develops the faculties given them by nature.

6. Both for medico-legal and educational purposes it is useful, and in some cases indispensable, to examine the condition of sensitiveness of a deaf mute, in order to determine his mental condition.

St. Clair Thomson.

\title{
ON THE PARACUSIS OF WILLIS.
}

\author{
By Dr. D'Aguanno (Palermo). \\ Read before the Fifth International Otological Congress at Florence.
}

Dr. D'Aguaxio referred to the various theories with regard to the causation of the paracusis of Willis. According to some authors, it arises from chronic lesions of the middle ear; according to others, from a peculiar torpor of the auditory nerve; while others again associate the torpor of the nerve with the lesions of the middle ear, thinking that in this way the question can be answered. Among the former, Von Tröltsch, while allowing that the majority of deaf patients hear better in the middle of noises, because one is obliged to speak to them in a louder voice than usual in a quiet room, cannot at the same time deny certain observations with regard to deafness which is truly "paradoxical," in which loud noises form the conditio sine quci non for hearing; and he explains these cases by a slight looseness of the joints of the chain.

Prof. Politzer, who determined that in these cases the amelioration was real because his acoumoter was heard better in the midst of noise, thinks that we have to deal with a rigidity of the chain of bones, which the loud noises succeed in shaking, and thus produce a better hearing power. Meanwhile, if the hypothesis of Tröltsch has not yet been demonstrated, that of Prof. Politzer is also very difficult to conceive. If we admit, in fact, that this paradoxical deafness is the consequence of a 